\title{
La integridad e independencia del Poder Judicial como garantía frente a la amenaza del Crimen Organizado Transnacional ${ }^{1}$
}

\author{
The integrity and independence of the Judicial \\ Power as a guarantee against the Threat of the \\ Transnational Organized Crime
}

Jordi Feo Valero y Salvador Herencia Carrasco²

\begin{abstract}
Resumen: A través del presente artículo, se ha llevado a cabo un análisis sobre los instrumentos de las Naciones Unidas existentes para el tratamiento del crimen organizado transnacional y la corrupción. De esta forma se pretende poner de manifiesto una serie de elementos que podrían ser de utilidad de cara a los resultados de la VIII Cumbre de las Américas, centrada en la corrupción y la gobernabilidad democrática. Si bien es necesario aumentar la cooperación internacional, las reformas legales e institucionales de los Estados están rezagadas frente a las distintas manifestaciones de esta criminalidad, por lo que se debe buscar otros medios más expeditos que permitan una respuesta por parte de las autoridades.
\end{abstract}

Palabras clave: Crimen organizado transnacional, Transnational Organised Crime, Corrupción

Abstract: This article analyzes the existing United Nations instruments used to cope with the issues arising from transnational organized crime and corruption. The aim therefore is to highlight a series of elements that could be useful in view of the results of the VIII Summit of the Americas, which focuses on corruption and democratic governance. Although it is necessary to increase international cooperation, legal and institutional reforms in the States are lagging behind the different manifestations of this phenomenon. Accordingly, it is necessary to find more expeditious means allowing the authorities to respond.

Key words: Corruption, Independencia Judicial, Judicial Independence, UN Special Rapporteur.

\footnotetext{
${ }^{1}$ Recibido: 04/04/2018. Aceptado: 30/07/2018

${ }^{2}$ Jordi Feo Valero es coordinador del Proyecto "UN Special Rapporteur for the Independence of Judges and Lawyers" del Human Rights Research and Education Center de la Universidad de Ottawa (Canadá). Email: jfeo@uottawa.ca. Salvador Herencia Carrasco es Director de la Clínica de Derechos Humanos del Human Rights Research and Education Center de la Universidad de Ottawa (Canadá). E-mail: shere045@uottawa.ca. Las opiniones presentadas en este artículo son a título personal y no comprenden ninguna de las instituciones mencionadas.
} 


\section{Introducción}

A lo largo de los últimos años, se ha producido una mayor preocupación acerca de la correlación existente entre la independencia del Poder Judicial y el alcance de la corrupción en el seno de esta rama del Estado (Van Dijk y Spapens, 2014, p. 7) El impacto de este fenómeno, conlleva no solamente la necesidad de contar con un Poder Judicial íntegro, eficaz e independiente, capaz de asegurar la protección los derechos y libertades fundamentales de las personas, sino que la sociedad lo perciba como tal. Así pues, un sistema judicial corrompido no solo priva a los ciudadanos de esa protección, comprometiendo el respeto a los derechos humanos, sino que contribuye a mermar la confianza de la sociedad civil en sus instituciones.

La corrupción, además de tener un impacto directo sobre el concepto de democracia y observancia de los derechos humanos (Koch Andersen, 2018, p. 7), tiene consecuencias directas sobre aquellos órganos encargados de asegurar el estado de derecho. En este sentido, el Poder Judicial en su conjunto, es un actor especialmente vulnerable debido a la importancia de las labores que desarrolla como salvaguarda del estado de derecho. Se puede afirmar que la corrupción judicial está en muchos casos íntimamente vinculada a la presión realizada por grupos delictivos organizados en aras de mermar la necesaria independencia que debe regir las actuaciones de este colectivo y favorecer la impunidad de sus crímenes.

Conviene tener en cuenta la correlación existente entre la impunidad del crimen organizado y la incapacidad de las instituciones para desempeñar sus funciones adecuadamente. Resulta por ello esencial que las capacidades institucionales de los Estados sean sólidas si se quieren abordar los retos que plantean los delitos transnacionales. A la luz del caso Odebrecht que viene afectando a varios países de América Latina, el crimen organizado no dudará en utilizar cualquier medio a su alcance para infiltrarse en los estamentos judiciales, políticos, económicos y sociales. Por lo tanto, solamente a través de unas instituciones fuertes y consolidadas democráticamente podrá hacerse frente a las prácticas corruptas derivadas de sus actividades.

Finalmente, resulta llamativo como a pesar de la existencia de una gran cantidad de iniciativas dirigidas a prevenir y combatir el crimen organizado y la corrupción (García Sayán, 2017, p. 6), pocas son aquellas que analizan el vínculo existente entre estos dos fenómenos. Es importante tener en cuenta que la Octava Cumbre de las Américas, realizada en abril de 2018, tuvo como tema la "Gobernabilidad democrática frente a la corrupción". Si bien la Declaración de Lima hace referencia a la corrupción como una amenaza transnacional, no se establecen mecanismos que fomenten acciones concretas sobre la materia (GRIC/CA-VIII/doc.2/17, 2017:, p.1)

Este es el punto de preocupación. Pues existe un sistema internacional que trata el fenómeno del crimen organizado y de la corrupción, pero la capacidad de respuesta del Estado es tardía e ineficiente, dando una ventaja a organizaciones criminales, particularmente las transnacionales. De ahí la necesidad de buscar espacios y herramientas más dinámicas que permitan una colaboración más efectiva entre Estados.

El propósito de este trabajo, ha consistido en hacer un análisis acerca de cómo el Derecho Internacional ha tratado el fenómeno de la criminalidad organizada, particularmente a través de instrumentos de las Naciones Unidas. Nuestra hipótesis es que un análisis priorizando el derecho penal es incompleta pues resulta necesaria la perspectiva 
de los derechos humanos, particularmente en la protección de la independencia del Poder Judicial y la gobernabilidad democrática.

En cuanto a la metodología utilizada para alcanzar este objetivo, las fuentes primarias analizadas han consistido esencialmente en el estudio de los textos legales internacionales considerados relevantes para el caso tratado a través del análisis de fuentes de derecho positivo, convencional, consuetudinario y documentos de "soft law" relevantes.

Con el fin de poner de manifiesto el estado y evolución de la situación analizada, se ha hecho referencia a lo largo de todo el estudio a las distintas manifestaciones del crimen organizado transnacional en tanto que amenaza a la integridad e independencia del poder judicial. Ello implica el examen de documentos e informes nacionales, de organismos y de organizaciones internacionales o de los mecanismos convencionales y extraconvencionales del sistema de las Naciones Unidas entre otros. Además, se ha analizado numerosa documentación proporcionada tanto por la sociedad civil como por los diferentes actores de la comunidad internacional.

\section{El tratamiento de la ONU a la corrupción y los delitos transna- cionales.}

La delincuencia organizada transnacional y el tráfico ilícito de drogas, armas, dinero y recursos naturales, así como la trata de personas, se han convertido en amenazas globales que socavan el estado de derecho y la buena gobernanza, obstaculizando el desarrollo sostenible (UNODC, 2018, web). Su influencia sobre los sistemas judiciales agrava aún más si caben estas amenazas al atacar directamente la estructura de defensa implementada por el estado de derecho para protegerse contra esas prácticas.

A la hora de encarar la problemática derivada de la corrupción, ha de tenerse en cuenta que se trata de una cuestión transversal que no puede desconocerse a la hora de abordar sus efectos en el sistema judicial. Este fenómeno puede llegar a socavar la independencia de las instituciones y de esta forma conducir a la impunidad de los delincuentes.

La comunidad internacional ha adoptado un conjunto de normas y políticas de carácter internacional desarrolladas a lo largo del tiempo ha posibilitado la creación de un marco de referencia en este ámbito. Estas Declaraciones, Pactos, Convenciones, Principios, Directrices, Protocolos, Resoluciones, Comentarios o Debates Temáticos, así como otras iniciativas llevadas a cabo constituyen la base del marco internacional de referencia puesto a disposición de los gobiernos con el fin de prevenir, hacer frente y revertir los efectos de la corrupción judicial causada por organizaciones criminales organizadas. ${ }^{3}$

\footnotetext{
${ }^{3}$ Entre las normas, principios y directrices que componen los estándares internacionales en el ámbito de la lucha contra la corrupción judicial conviene destacar: la Declaración Universal de Derechos Humanos (1948), el Pacto Internacional de Derechos Civiles y Políticos (1966), los Principios básicos relativos a la independencia de la judicatura (1985), los Principios Básicos sobre la Función de los Abogados (1990), las Directrices sobre la función de los fiscales (1990), la Convención de las Naciones Unidas contra la Delincuencia Organizada Transnacional (2000), el Protocolo para prevenir, reprimir y sancionar la trata de personas, especialmente mujeres y niños, que complementa la Convención de las Naciones contra la Delincuencia Organizada Transnacional (2000), el Protocolo contra el tráfico ilícito de migrantes por tierra, mar y aire, que complementa la Convención de las Naciones Unidas contra la Delincuencia Organizada Transnacional (2000), el Protocolo contra la fabricación y el tráfico ilícitos de armas de fuego, sus piezas y componentes y municiones, que complementa la Convención de las Naciones Unidas contra la Delincuen-
} 
El sistema de Naciones Unidas, ha desarrollado dos convenciones que sirven como marco de referencia a la hora de analizar la relación existente entre el crimen organizado y la corrupción judicial. Se trata de la Convención de las Naciones Unidas contra la Delincuencia Organizada Transnacional y sus protocolos- UNTOC y la Convención de las Naciones Unidas contra la Corrupción- UNCAC.

La Convención de las Naciones Unidas contra la Delincuencia Organizada Transnacional y sus tres Protocolos, constituyen las herramientas principales para afrontar los retos creados derivados de la delincuencia organizada transnacional. El artículo 1 de la Convención establece que su propósito consiste en: "promover la cooperación para prevenir y combatir más eficazmente la delincuencia organizada transnacional" A lo largo del texto, varios son los preceptos que recogen el vínculo existente entre la delincuencia organizada transnacional y la corrupción. Así pues el artículo 8 urge a los estados a penalizar las prácticas corruptas, mientras que el artículo 9 recoge algunas medidas para hacer frente a esta lacra, entre las que se citan "medidas eficaces de carácter legislativo, administrativo o de otra índole para promover la integridad y para prevenir, detectar y castigar la corrupción de funcionarios públicos" (A/RES/55/25, 2001, p. 4)

Por su parte, la Convención de las Naciones Unidas contra la Corrupción supuso un hito importante a nivel internacional en el ámbito de la lucha contra la corrupción. La UNCAC establece un conjunto de normas y medidas con el fin de fortalecer los regímenes jurídicos y reglamentarios para luchar contra la corrupción. Este texto realiza un llamamiento a los Estados parte para que adopten medidas preventivas en el ámbito de sus leyes, instituciones y prácticas, incluyendo la cooperación internacional. Asimismo, se promueve la criminalización de las formas más comunes de corrupción tanto en el sector público como en el privado (Argandoña, 2006, p. 9 y ss.) El amplio alcance de la UNCAC, así como el carácter vinculante de muchas de sus disposiciones la convierten en una herramienta única para implementar una respuesta integral a un problema mundial (UNCAC, 2017, web)

El Preámbulo de la UNCAC, evidencia la toma de conciencia de la comunidad internacional ante "la gravedad de los problemas y las amenazas que plantea la corrupción para la estabilidad y seguridad de las sociedades al socavar las instituciones y los valores de la democracia, la ética y la justicia y al comprometer el desarrollo sostenible y el imperio de la ley" Además, los Estados consideraron oportuno plasmar la relación y los vínculos existentes entre "la corrupción y otras formas de delincuencia, en particular la delincuencia organizada". Del mismo modo, el documento se hace eco de la dimensión transnacional que ha adquirido este fenómeno señalando que: "la corrupción ha dejado de ser un problema local para convertirse en un fenómeno transnacional que afecta a todas las sociedades y economías, lo que hace esencial la cooperación internacional para prevenirla y luchar contra ella" (A/RES/58/4, 2006, p. 4)

Este texto se ha convertido en el eje de las iniciativas nacionales e internacionales de lucha contra la corrupción, al promover la implementación y aplicación de las normas comunes y mejores prácticas. Varios de los principios y obligaciones del UNCAC deberían

cia Organizada Transnacional (2001), los Principios de Bangalore sobre la conducta judicial (2002), la Convención de las Naciones Unidas contra la Corrupción (2003), el Dialogo Temático de la Asamblea General sobre "Las drogas y el crimen: una amenaza para el desarrollo" (2012), la Agenda 2030 para el Desarrollo Sostenible, en concreto el Objetivo 16 (2015). 
ser considerados más sistemáticamente e incluidos en la agenda mundial de derechos humanos. En este sentido, los organismos más estrechamente vinculadas con el seguimiento y la aplicación de esta convención que integran el sistema de las Naciones Unidas, como la Oficina de las Naciones Unidas contra la Droga y el Delito, están dando pasos muy positivos por su cuenta.

La UNODC es la oficina encargada de articular esfuerzos en la lucha contra las drogas ilícitas y la delincuencia organizada transnacional y se instituyó con objeto de ejecutar de una manera integrada su programa contra la droga ${ }^{4}$ y su programa contra el delito ${ }^{5}$, y hacer frente así a las cuestiones interrelacionadas de la fiscalización de drogas, la prevención del delito y el terrorismo internacional en el marco del desarrollo sostenible y la seguridad humana (ST/SGB/2004/6, 2004, p. 1) En 1999, la UNODC adoptó su "Global Programme against Corruption: an outline for action". Este programa, entre sus líneas de investigación, hace una referencia concreta a la necesidad de llevar a cabo estudios sobre la corrupción en el sistema de justicia (UNODC, 1999, p.7) Posteriormente, en el año 2004, se creaba el "Manual de Herramientas Contra la Corrupción", haciendo especial referencia a la importancia de los efectos de la corrupción judicial en el ámbito de la lucha contra la corrupción (UNODC, 2004, p. 49 y ss.)

En el año 2000, la Asamblea de Naciones Unidas aprobó la Declaración del Milenio, en la cual los Estados Miembros resolvieron intensificar la lucha contra la delincuencia organizada transnacional en todas sus dimensiones (A/RES/55/2, 2000, p.3) Posteriormente, en el año 2005, la Asamblea General de Naciones Unidas quiso dejar latente su "grave preocupación por los efectos negativos que [la Corrupción] tiene para el desarroIlo, la paz y la seguridad y los derechos humanos la delincuencia transnacional... así como por la creciente vulnerabilidad de los Estados a ese tipo de delincuencia" (A/RES/60/, 2005 , p. 28) Es más, este organismo consciente de la influencia que los delitos transnacionales pueden tener sobre la corrupción judicial instaba a aquellos estados que aún no lo hubieran hecho, no solamente a adherirse a las convenciones internacionales sobre delincuencia organizada y corrupción, sino a reforzar sus sistemas judiciales (A/RES/60/, 2005, p. 29) Finalmente, en el año 2015 la Asamblea General de Naciones Unidas aprobó la Agenda 2030 para el desarrollo sostenible e integró estas prioridades en el Objetivo 16 bajo el título: "Promover sociedades pacíficas e inclusivas para el desarrollo sostenible, facilitar el acceso a la justicia para todos y construir a todos los niveles instituciones eficaces e inclusivas que rindan cuentas" (A/70/L.1, 2015, p. 16)

En relación con el problema que nos ocupa, la Conferencia de las Partes en la Convención de las Naciones Unidas contra la Delincuencia Organizada Transnacional, celebrada en Viena del 17 al 21 de octubre de 2016 resaltó que :"la asistencia técnica que

\footnotetext{
${ }^{4}$ El Programa de las Naciones Unidas para la Fiscalización Internacional de Drogas se instituyó en virtud de la resolución 45/179 de la Asamblea General, de 21 de diciembre de 1990, como órgano encargado de coordinar la labor internacional de lucha contra el abuso de drogas. La Asamblea General confirió al Director Ejecutivo la autoridad sobre el Fondo del Programa en su resolución 46/185 C, de 20 de diciembre de 1991.

${ }^{5}$ El Programa de las Naciones Unidas en materia de prevención del delito y justicia penal fue establecido por la Asamblea General en su resolución 46/152, de 18 de diciembre de 1991. Desde 1997, la ejecución del Programa ha estado a cargo del Centro de Prevención Internacional del Delito, establecido conforme a lo dispuesto en la sección $V$ de la segunda parte del programa de reforma del Secretario General, que se expone en el documento A/51/950, de fecha 14 de julio de 1997.
} 
presta la UNODC a los Estados para aplicar la Convención contra la Delincuencia Organizada y sus Protocolos es una parte integral de las metas previstas en muchos de los objetivos de la Agenda 2030 para el Desarrollo Sostenible" (CTOC/COP/2016/10, 2016, p. 16)

A lo largo de este apartado, hemos puesto en evidencia la relación existente entre el crimen organizado y la corrupción. En este sentido, el Boletín del Secretario General que constituyó la UNODC decidió crear dentro de esta oficina una División de Tratados. Entre las funciones de este organismo destaca la de desempeñar "las funciones de secretaría de la Conferencia de las Partes en la Convención de las Naciones Unidas contra la Delincuencia Organizada Transnacional y la Conferencia de las Partes en la Convención de las Naciones Unidas contra la Corrupción" (ST/SGB/2004/6, 2004, p. 4)

A través de esta iniciativa, el Secretario General de las Naciones Unidas centralizó en un único organismo la coordinación derivada los aspectos subyacentes a interrelación existente entre ambos conceptos, mejorando de este modo la eficacia de las iniciativas a implementar a la hora de hacer frente a estos fenómenos. Así pues, baste mencionar a título de ejemplo como durante la Conferencia de las Partes en la Convención de las Naciones Unidas contra la Delincuencia Organizada Transnacional, celebrada en Viena del 17 al 21 de octubres de 2016, el Grupo de trabajo sobre cooperación internacional solicitaba que se tuviera en cuenta: "la labor realizada al respecto en la Convención de las Naciones Unidas contra la Corrupción" (CTOC/COP/2016/15, 2016, p. 10)

\section{Los conceptos de crimen organizado transnacional y corrupción en el marco de la Organización de las Naciones Unidas.}

Antes de entrar a analizar las nociones de crimen organizado transnacional y corrupción, conviene hacer referencia al hecho de que nos encontrados ante dos conceptos jurídicamente indeterminados. Como veremos a lo largo de este epígrafe, los grupos de trabajo encargados de presentar las dos Convenciones que debían regularlas, consideraron oportuno, en aras de lograr una mayor adhesión a estos instrumentos jurídicos, no presentar una definición que pudiera encorsetar lo que debía entenderse por estos conceptos.

Se considera que un grupo delictivo organizado es de carácter nacional cuando la actividad que desarrolla se realiza en un territorio concreto que abarca las fronteras de un determinado país. A esto hay que añadirle que las actividades referidas tienen efectos exclusivamente sobre ese ámbito territorial. Por su parte, el crimen organizado tendrá carácter transnacional cuando se produzca "una operatividad a escala mundial, unas conexiones transnacionales extensivas y, sobre todo, por la capacidad de retar a la autoridad nacional e internacional" (Resa Nestares, 2005, web)

El Relator Especial sobre la independencia de magistrados y abogados, considera que esta transnacionalidad es "consecuencia directa del proceso de globalización que se ha producido a escala mundial, lo que complica enormemente la lucha y coordinación de los diferentes estados y organismos en este ámbito" (A/72/140, 2017, p. 9) Esta característica permite que el crimen organizado lleve a cabo sus actividades desde cualquier lugar del mundo, actuando con la misma solvencia que las empresas transnacionales, vinculándose a estas o incluso compitiendo por un segmento del mercado (Flores Pérez, 2007, p. 14) 
A nuestro entender, hoy en día la diferenciación entre crimen organizado nacional y transnacional se ha visto superada por el contexto de globalización mundial mencionada anteriormente. Esta clasificación, que podía tener sentido hace algunas décadas, ha quedado obsoleta, además de por la proliferación de instituciones supranacionales y los vínculos que conllevan entre sus estados miembros, por el desarrollo tecnológico.

Así pues, nos encontramos en un contexto en el que no solamente se pueden llevar a cabo actos ilícitos desde cualquier lugar del mundo, sino desde una plataforma virtual en la que el lugar físico desde el que se actúe tiene cada vez menos importancia a la hora de combatir estas actuaciones. Este hecho de enfrentarse ante un problema que abarca más allá de las fronteras de los Estados soberanos presenta una serie de retos a tener en cuenta a escala global. Esta característica hace imperativo que se produzca una coordinación internacional si se quiere dar respuesta de manera efectiva a los retos y dificultades que subyacen.

En cuanto a los conceptos que se analizan propiamente dichos, la UNTOC recoge las características que debe reunir un "grupo delictivo organizado". Concretamente, la Convención establece que se trate de un grupo "estructurado", lo que implica que no se haya formado puntualmente para un acto determinado y que su disolución no se produzca una vez realizado el acto delictivo. Las actividades llevadas a cabo por este tipo de organizaciones deben consistir en la realización continuada de actos ilícitos que hayan sido planificados anteriormente para poder ser llevados a cabo.

De acuerdo con el artículo 2 b) de la Convención su actuación no solamente deberá de ser premeditada sino que las acciones que realicen deben poder integrarse en el tipo penal de los delitos graves, es decir que conlleven penas privativas de libertad de cuatro años o más. Además, solamente podrá considerarse que se trata de un "grupo delictivo organizado" si el producto del delito lo constituyen "activos de cualquier tipo, corporales o incorporales, muebles o inmuebles, tangibles o intangibles, y los documentos o instrumentos legales que acrediten la propiedad $u$ otros derechos sobre dichos activos de cualquier índole derivados $u$ obtenidos directa o indirectamente de la comisión de un delito" (A/RES/55/25, 2000, p. 4)

Una vez llegados a este punto resulta conveniente hacer referencia al hecho de que la UNODC entiende que la UNTOC, "no contiene una definición precisa del término "crimen transnacional organizado" ni incluye una lista de los tipos de delitos que podrían constituirlo" (UNODC, 2018, web), lo que convierte al crimen organizado transnacional, tal y como hemos mencionado anteriormente, en un concepto jurídico indeterminado. Lo que en un primer momento podría ser interpretado como una falta de rigor a la hora de elaborar la normativa internacional en esta materia es en realidad una decisión acertada que permite sortear la rigidez intrínseca de los conceptos jurídicos determinados. En este caso concreto nos encontramos ante una herramienta que, gracias a su indeterminación jurídica, es capaz de adaptarse a la evolución tecnológica y geoestratégica que caracterizan a este tipo de delitos, permitiendo de este modo que ciertas conductas delictivas tengan cabida en una norma de derecho internacional. Podemos afirmar por lo tanto que "la definición tácita de crimen transnacional organizado incluye virtualmente a todas las actividades criminales serias con fines de lucro y que tienen implicaciones internacionales" (UNODC, 2018, web)

Al igual que ocurrió con la UNTOC, la UNCAC, en aras de lograr un consenso para la aprobación de este instrumento jurídico, decidió no establecer una definición globalmen- 
te aceptada de lo que debe entenderse por corrupción. Los redactores de la misma optaron por elaborar un listado de tipos concretos de actuaciones que puedan ser considerados como corrupción (UNODC, 2004, p 11) El hecho de que el concepto de corrupción no esté claramente definido, conlleva que algunas prácticas que pudieran parecernos corruptas podrían no ser tipificadas como tales en ciertos lugares y en base situaciones socio-culturales diferentes a las de nuestro entorno.

En este sentido, los artículos 15 a 25 de la UNTOC $^{6}$ enuncian una serie de actuaciones que deben ser consideradas como corruptas. Las mismas engloban desde el soborno de funcionarios públicos nacionales hasta la obstrucción a la justicia. La mayoría de las conductas recogidas son de aplicación a la actuación de los funcionarios públicos, por lo que son de directa aplicación a las actuaciones desarrolladas por los funcionarios de justicia. Conviene hacer referencia asimismo al hecho de que la UNODC diferencia entre la gran y la pequeña corrupción. Así pues, puede entenderse por gran corrupción aquella que penetra en los más altos niveles de un gobierno nacional conduciendo a una amplia erosión de la confianza en el buen gobierno, el imperio del derecho y la estabilidad económica. Por su parte, la pequeña corrupción puede ser entendida como aquella que conlleva el intercambio de pequeñas cantidades de dinero, la concesión de pequeños favores por parte de los que buscan un trato especial o la contratación de parientes o amigos en posiciones menores.

El Manual de Herramientas contra la Corrupción, elaborado por la UNODC establece que la principal diferencia entre la gran corrupción grande y la pequeña es que la primera implica "la distorsión o corrupción de las funciones centrales de gobierno, mientras que la última se desarrolla y existe dentro del contexto de la gobernabilidad y trama social establecidas" (Carranza, 2007, p.4)

Llegados a este punto, hemos podido constatar como la normativa internacional ha considerado oportuno establecer un marco normativo lo suficientemente flexible que permita integrar a lo largo del tiempo no solamente la evolución terminológica de los conceptos analizados, sino también las necesarias interrelaciones que se producen entre los mismos. Hay que tener en cuenta que conforme se va produciendo una evolución de la calificación de los tipos penales como consecuencia de las nuevas circunstancias que surgen a nivel socioeconómico y político, las características de ciertos hechos delictivos se solapan dificultando la tipificación de ciertos hechos delictivos en un sentido o en otro. Además hay que tener en cuenta que, tal y como afirma Catalina Uribe Bucher, "en la realidad y de manera creciente el crimen organizado está involucrado en actividades que no son típicamente ilegales, pero donde se abusa sistemáticamente de la ley" (2015, p.24)

\footnotetext{
${ }^{6}$ Estos artículos recogen las siguientes conductas: Soborno de funcionarios públicos nacionales; Soborno de funcionarios públicos extranjeros y de funcionarios de organizaciones internacionales públicas; Malversación o peculado, apropiación indebida u otras formas de desviación de bienes por un funcionario público; Tráfico de influencias; Abuso de funciones; Enriquecimiento ilícito; Soborno en el sector privado; Malversación o peculado de bienes en el sector privado; Blanqueo del producto del delito; Encubrimiento y Obstrucción de la justicia.
} 


\section{Vinculación entre política, crimen organizado transnacional y corrupción judicial}

A pesar de que el crimen organizado transnacional, utiliza diferentes estrategias para infiltrarse en el aparato del Estado se ha constatado que una tendencia común para hacerlo es a través de la corrupción (Briscoe I., Perdomo, C., Uribe Burcher C. 2015, p. 237) La Convención Interamericana Contra la Corrupción reconoce que: "la corrupción es uno de los instrumentos que utiliza la criminalidad organizada con la finalidad de materializar sus propósitos" (OEA, 1996)

Existe un amplio consenso acerca de las características que deben reunir ciertas conductas realizadas para que puedan ser calificadas de corruptas. Este consenso se basa en la definición de Joseph S. Nye que, aplicada al ámbito del sistema judicial, podría definirse como aquel comportamiento que se aparta de los deberes normales del personal integrante del sistema de justicia debido a que atiende a lo privado o ganancias pecuniarias o de estatus; o quebranta las reglas en contra del ejercicio de ciertos tipos de influencia que atienden a lo privado (1967, p. 966)

Antes de analizar al impacto del crimen organizado en el Poder Judicial, es importante hacer referencia a la fortaleza, independencia y credibilidad que esta institución debe de tener para cumplir con su mandato constitucional. En este sentido, el gráfico que se expone a continuación gradúa por regiones la independencia judicial, en tanto que elemento clave para asegurar la eficacia del Poder Judicial en su lucha contra el crimen organizado transnacional y los derechos humanos.

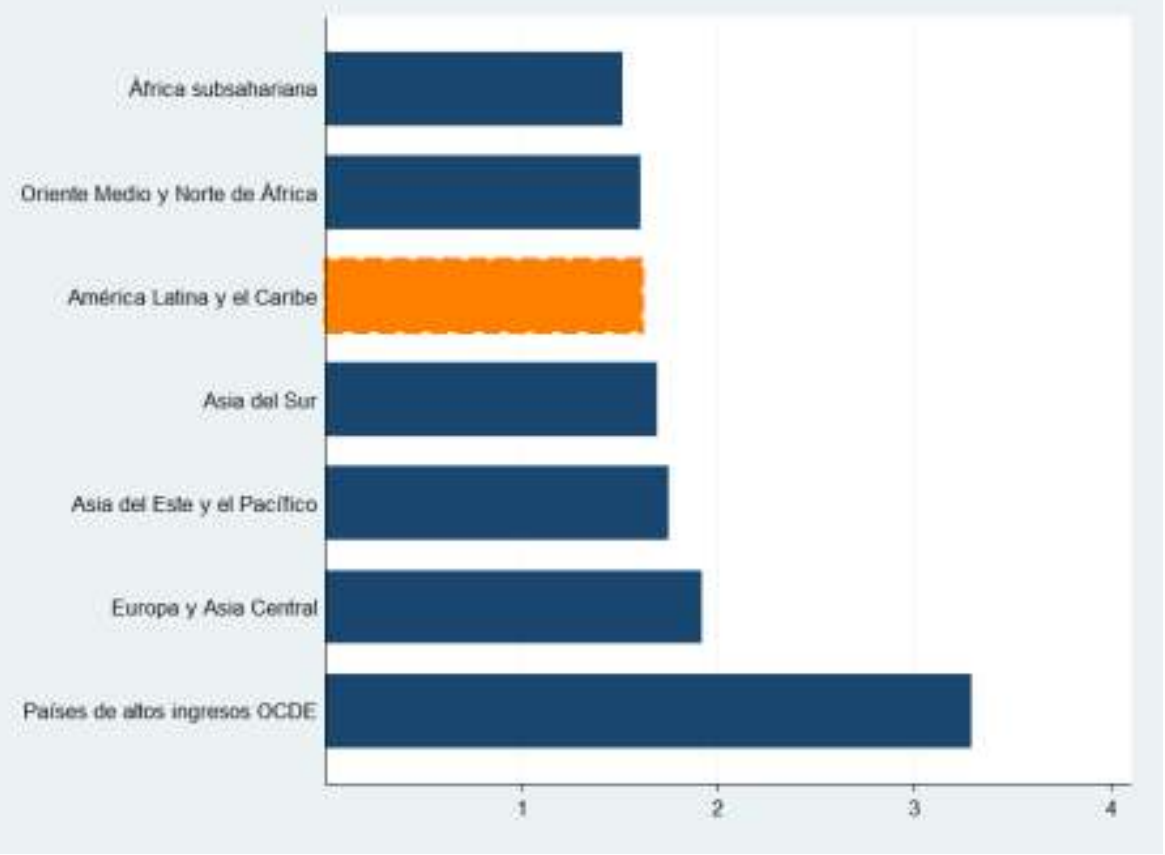

Fuente: Franco Chuaire y Scartascini (2014) 
Si excluimos los países de altos ingresos de la OCDE, vemos como en el resto de regiones del mundo la percepción sobre la independencia y la capacidad del poder judicial para desarrollar sus funciones dista mucho de ser idónea.

Tal y como se puede observar en el gráfico, en el caso de América Latina, la independencia y fortaleza del Poder judicial sigue constituyendo un reto para la región. Este extremo se ve corroborado por los datos presentados por la Corporación Latinobarómetro, en el que se pone de manifiesto que la mayoría de los ciudadanos no confían en su sistema de justicia.

En su informe de 2017, el 31\% de las personas en Brasil consideran que la corrupción es el problema más grave de su país. Lo siguen Colombia (20\%), Perú (19\%) y República Dominicana (15\%). Sin embargo, al consultar si se considera si es que se ha progresado en la lucha contra la corrupción en los últimos 2 años, 62\% de las personas en el continente consideran que no se ha progresado. Los países con los índices más bajos son Venezuela, El Salvador, México y el Perú.

Estos datos son preocupantes, pues ponen de manifiesto el descontento que se ha producido por parte de la ciudadanía hacia el Estado y sus compromisos contra la corrupción. En lo referente a la corrupción percibida a nivel regional en los tribunales de justicia, el promedio alcanza el 7.4/10. La percepción de corrupción en los tribunales de justicia es aún mayor en el Perú (8.2/10), Venezuela (8.1/10) y Honduras (8/10) (Corporación Latinobarómetro, 2017, p. 36-39)

Es interesante hacer la comparación de estos datos con el promedio regional entre 1995 y el 2015. Nuevamente al utilizar los datos del Latinobarómetro, se constata que la confianza en el Poder Judicial ha oscilado entre el $21 \%$ y el $40 \%$, situándose en el año 2015 en un 30\% (2015: 6-9). Esta estadística regional indica que la mayoría de las personas en América Latina no confía en el Poder Judicial, sugiriendo que esta institución sería percibida como incapaz de afrontar el procesamiento e investigación de casos de corrupción, especialmente los relativos a la criminalidad organizada transnacional.

En este contexto, es importante resaltar que funcionarios, empleados públicos y políticos son los estamentos más expuestos a las presiones realizadas por parte de las redes criminales transnacionales. A través de sus prácticas corruptas y coactivas, estas organizaciones buscan conseguir influenciar las actuaciones de aquellos actores que pudieran beneficiar sus transacciones ilegales y encubrir sus conductas criminales. Estas redes son complejas no sólo por su tamaño, sino por su capacidad para penetrar y manipular múltiples facetas de la sociedad (Sullivan, J. P., 2016, p. XXIV) De acuerdo con Catalina Perdomo, la presencia e influencia en escenarios públicos y políticos, es una de las tantas estrategias que el crimen organizado busca para disfrazar su carácter delictivo (2015, p. 237)

Tal y como puso de manifiesto la Corte Plena del Poder Judicial de Costa Rica en el año 2014, "las redes criminales se extienden a lo interno de la institucionalidad imponiendo su poder y su influencia a partir de sus propias reglas, creando esferas de inmunidad e impunidad desde el propio Estado" (Corte Plena, 2014, p. 226) Este "modus operandi" conlleva que uno de sus objetivos más preciados sea el de lograr penetrar institucionalmente en el sector judicial para permitirles, llegado el momento, disponer de una amplia esfera de influencia capaz de ampliar el cordón de seguridad alrededor de la protección de sus intereses. 
Una de las principales actuaciones a través de la cual el crimen organizado transnacional logra permear la independencia del Poder Judicial consiste en fomentar la corrupción política. Debido a las características intrínsecas de las sociedades democráticas y a los procesos de designación de los representantes públicos y los órganos que deben asegurar el correcto funcionamiento de la administración pública, la política se convierte en una esfera de influencia con capacidad de acceso a las tres ramas del estado. De este modo, una vez que el crimen organizado logra tejer una red de contactos lo suficientemente amplia en el ámbito político, se encuentra en una posición de fuerza para poder lograr la cobertura necesaria que le asegurará poder llevar a cabo sus actividades ilícitas sin tener que responder por las mismas.

A modo de ejemplo, baste citar el conocido como caso "Fujimori-Montesinos". Dado que un objetivo prioritario de la organización criminal era perpetuarse en el poder, el control del aparato electoral resultaba primordial, ya que permitía controlar a los legisladores una vez elegidos por el pueblo. Una vez que culminó la correspondiente investigación sobre la red criminal creada desde los más altos estamentos del estado, el presidente del Jurado Electoral y un magistrado de ese tribunal, así como el jefe de la Oficina Nacional de Procesos Electorales (ONPE), fueron condenados a prisión. De acuerdo con Salcedo-Albarán y Garay-Salamanca, dado que, a pesar de la red tejida Fujimori no obtuvo mayoría parlamentaria suficiente, durante su segundo período decidió "comprar literalmente a congresistas de la oposición a fin de completar el número de votos necesarios para poder legislar y controlar el Parlamento, sin necesidad de pactos políticos con otras agrupaciones" (2016, p. 42)

A nadie se le escapa el por qué la corrupción política se ha convertido a día de hoy en una de las herramientas más eficaces para que los delitos transnacionales puedan llevarse a cabo (Alt y Lassen, 2008) Basta simplemente analizar la prensa internacional y las diferentes tramas que han salido a la luz en este sentido para constatar el vínculo cada vez más estrecho que se produce entre ambos grupos. Llegados a este punto es conveniente resaltar como en muchas ocasiones, los fenómenos delictivos a los que se hace referencia "no nacen alejados de las instituciones de sus países, sino que representan de diferentes maneras el resultado directo o sub-producto del modo mismo de funcionamiento de sus Estados" (Briscoe I, Catalina Perdomo C., Uribe Burcher C., 2015, p. 63)

Es pues, a través de la corrupción judicial que los políticos corruptos se ven amparados por la impunidad que les otorga el sistema. Tal y como recogió el Relator Especial sobre la independencia de magistrados y abogados en su informe presentado ante la Asamblea General de las Naciones Unidas “desde esta posición de poder los políticos corruptos pueden servir de intermediarios al crimen organizado con el fin de encubrir actividades ilícitas que les permiten garantizar sus beneficios" (García Sayán, 2017, p. 12) En el sentido inverso, y de acuerdo con la información analizada por Edgardo Buscaglia y Jan van Dijk, puede afirmarse que la independencia judicial está íntimamente relacionada con los niveles de delincuencia organizada en el sentido de que cuanto mayor es la independencia judicial menor es el impacto del crimen organizado tanto sobre el estamento judicial como sobre los otros poderes del Estado (2003, 12 y 15)

Finalmente, sería conveniente poner de manifiesto la complejidad intrínseca que conlleva la lucha contra la corrupción en general y judicial en particular. Las principales dificultades en este ámbito tienen que ver con la ausencia de pruebas "prima facie" y la facilidad que tiene el fenómeno de la corrupción para permear en la mayoría de las insti- 
tuciones. Este hecho es especialmente relevante en el ámbito judicial, ya que la corrupción en una parte del sistema puede menoscabar considerablemente los esfuerzos que se realizan a nivel global para luchar contra la impunidad $(A / 65 / 274,2010$, p.18)

\section{Impacto del crimen organizado en la independencia judicial y en los derechos humanos}

La corrupción judicial tiene una influencia directa sobre la percepción social de la justicia, el estado de derecho y su capacidad para garantizar la protección de los derechos humanos. Únicamente a través de un sistema democrático basado en los principios de separación de poderes que fomente una judicatura libre e independiente se podrá hacer frente a los retos que plantea la delincuencia organizada. En este sentido, la exRelatora Especial sobre la independencia de magistrados y abogados, Sra. Gabriela Knaul, en su informe presentado ante la Asamblea General de las Naciones Unidas en el año 2012, destacó como "una judicatura de integridad indiscutible es una institución esencial para garantizar el respeto de la democracia y el estado de derecho" $(2012,6)$

La corrupción judicial, puede degenerar en determinadas ocasiones en una impunidad amparada por la conducta desviada de los distintos estamentos que integran el Poder Judicial (Carbonell, 2014, p. 1), situando este comportamiento en la base de la garantía de protección que persiguen estos grupos criminales. Un sector judicial éticamente vulnerable conlleva que los mecanismos legales e institucionales diseñados para hacer frente a la corrupción, a pesar de que en la teoría cumplan con todas las garantías necesarias, sean ineficaces al estar viciados por la influencia externa (UNODC, 2018, web).

El Sistema Interamericano de Derechos Humanos, se ha situado a la vanguardia de otros sistemas regionales en varios ámbitos (Esteve Moltó, 2016), entre los que se encuentra el analizado en el presente artículo al reconocer la garantía de la independencia judicial como un derecho humano. Así pues, el artículo 8.1 de la Convención Americana sobre Derechos Humanos, establece que: "toda persona tiene derecho a ser oída, con las debidas garantías y dentro de un plazo razonable, por un juez o tribunal competente, independiente e imparcial" (Conferencia Especializada Interamericana sobre Derechos Humanos,1969)

En esta misma línea, la Comisión Interamericana de Derechos Humanos (CIDH) publicó en el año 2018 una Resolución sobre Corrupción y Derechos Humanos en la cual se establece que:

La lucha contra la corrupción está indisolublemente ligada al ejercicio y disfrute de los derechos humanos. La impunidad fomenta y perpetúa los actos de corrupción. Por lo tanto, el establecimiento de mecanismos efectivos para erradicar la corrupción es una obligación urgente para lograr un acceso efectivo a una justicia independiente e imparcial y para garantizar los derechos humanos". (CIDH, 2018, p.2)

Asimismo, la resolución $1 / 18$ a la que se acaba de hacer referencia no solo reafirma esta posición de la $\mathrm{CIDH}$ sino que destaca el pleno respeto de los derechos humanos en los procesos de investigación y enjuiciamiento de casos, la necesidad de acceso a la información y transparencia así como el fomento de mecanismos de participación ciudadana. 
Únicamente un Poder Judicial independiente, correctamente administrado y basado en la seguridad jurídica podrá cumplir con su papel de garante institucional del estado de derecho. Organizaciones internacionales como la "Hoover Institution" han puesto de manifiesto como la falta de previsibilidad de las resoluciones judiciales puede estar ligada a la corrupción judicial y a las actividades delictivas organizadas (Buscaglia, González-Ruiz y Ratliff, 2005, p. 19) Es precisamente en este contexto de falta de control e inseguridad jurídica, donde el crimen organizado encuentra el entorno idóneo para desarrollar su influencia sobre el sector judicial. A través de la corrupción de la judicatura se impide que esta institución actúe como garante en materia de corrupción, lo que beneficia a las redes criminales transnacionales que ven como su influencia en los estamentos del Estado se desarrolla con mayor facilidad (Fride, 2010, p. 2)

El sistema judicial se constituye en un elemento imprescindible para que el crimen organizado pueda llevar a cabo sus actividades ilegales, repercutiendo necesariamente sobre el impacto que los delitos transnacionales tienen sobre la corrupción judicial. Dado que el Poder Judicial tiene entre sus funciones garantizar que las actuaciones y comportamientos realizados en una sociedad basada en el estado de derecho se ajustan a la legalidad, este trabajo únicamente podrá llevarse a cabo si se asegura la independencia e imparcialidad del personal que integra el sistema a la hora de la tomar las decisiones. Al hilo de lo que acabamos de mencionar, la corrupción del personal de justicia conlleva que se desvirtúe no solamente el principio de independencia judicial sino también el de igualdad ante la ley al favorecerse a una de las partes. En consecuencia, se produce un ataque contra el derecho a la tutela judicial efectiva y a los principios básicos que deben informar la actividad de la administración de justicia en toda sociedad democrática.

Los jueces y el personal que integran la administración de justicia deben ser capaces de tomar sus decisiones libres de interferencias. Si el Poder Judicial se ve influenciado para favorecer a un grupo determinado, o para tomar partido por una de las partes de un caso, el proceso judicial se habrá corrompido. La imparcialidad y la independencia de jueces y magistrados se convierten de este modo no solamente en imposiciones legales que rigen el correcto funcionamiento del sistema judicial, sino en las garantías fundamentales del estado de derecho que permiten asegurar el respeto de los derechos humanos. Por su parte, Leandro Despouy, en su informe de fecha 31 de diciembre de 2003, identificó como la corrupción judicial tenía varias facetas que iban desde la influencia sobre la administración interna del Poder Judicial hasta la intervención tendenciosa en los procesos y resoluciones (E/CN.4/2004/60, 2003, p. 15). En esta línea, el "Foro sobre el Delito y la Sociedad", señaló entre los factores más significativos que permiten que la delincuencia organizada se infiltre en el sistema judicial, la complejidad procesal y los abusos de la discrecionalidad sustantiva de los jueces (UNODC, 2003, p.12)

El margen de discrecionalidad que las normas dejan en manos del juez le permite disponer de un cierto espacio de maniobra a la hora de fundamentar sus decisiones. Es muy importante tener en cuenta que, tal y como afirma Manuel Bellido Aspas, "esta capacidad de discrecionalidad del juez en modo alguno puede convertirse en una decisión arbitraria" (Bellido, 2006, p. 572) Es precisamente este "ámbito jurídico indeterminado" el lugar más codiciado por las organizaciones criminales a la hora de ejercer su influencia. De este modo, las redes delictivas transnacionales tratan de: "lograr, a través de la inacción o la interpretación viciada de la ley por parte de los actores integrantes del 
sistema de justicia, encubrir o dotar de legitimidad las actividades delictivas llevadas a cabo" (A/72/140, 2017, p.16)

Los grupos delictivos organizados, buscarán por cualquier medio influir sobre el estamento judicial y lograr la cobertura que necesitan para llevar a buen puerto sus actividades ilícitas. La influencia en el Poder Judicial a través de su corrupción constituye la forma más efectiva de dirigir a jueces y magistrados a la hora de decidir o de tomar en consideración los diferentes asuntos que son de su interés. Resulta por lo tanto esencial que los estados reconozcan el papel particular y la vulnerabilidad de las instituciones del sector de la justicia en lo que respecta a la corrupción causada por el crimen organizado transnacional y colaboren en la creación de instituciones judiciales verdaderamente independientes, éticas y responsables.

Tal y como reflejaron en el año 2016 Eduardo Salcedo-Albarány Luis J. GaraySalamanca en su obra "Macro-criminalidad: Complejidad y Resiliencia de las Redes Criminales" en relación con el caso peruano, la administración de justicia juega un papel relevante en la estrategia de las organizaciones criminales. Gracias a la influencia de estos grupos sobre el poder judicial, el crimen organizado trata de garantizar no solo la impunidad de sus miembros sino la obtención de fondos producto de la extorsión a litigantes involucrados en procesos complejos (2016, p. 41)

No debemos perder de vista el hecho de que el crimen organizado transnacional, mediante sus prácticas delictivas y corruptas, merma el Estado de derecho y el desarrollo sostenible de las sociedades a través de sus efectos perjudiciales y destructivos. Estas consecuencias son especialmente graves cuando se socava el sector de la justicia, que debe basarse en los principios de independencia, imparcialidad, integridad e igualdad (UNODC, 2018, web) Es en este contexto de falta de control e inseguridad jurídica donde el crimen organizado encuentra el entorno ideal para desarrollar su influencia sobre el sector judicial. Actuando sobre los principios que deben regir la actuación del Poder Judicial el crimen organizado impide que esta institución actúe como guardián en materia de corrupción, beneficiando de este modo a las redes criminales transnacionales que ven como su influencia en los estamentos del Estado se lleva a cabo con mayor facilidad (Fride, 2010, p.2)

\section{Conclusiones y elementos para una solución a largo plazo}

El crimen organizado transnacional, a través de sus prácticas delictivas y corruptas, busca mermar el estado de derecho y el desarrollo sostenible a través de sus efectos perjudiciales y destructivos. Estas consecuencias son especialmente graves cuando se socava el sector de la justicia, ya que los grupos criminales organizados buscan a través de la corrupción judicial influir directamente sobre los principios de independencia, imparcialidad, integridad e igualdad que deben regir el sistema judicial en aras de garantizar la aplicación imparcial de la justicia.

A lo largo de este trabajo, hemos podido ver como las amenazas transnacionales representan un peligro global en tanto que facilitadores de prácticas corruptas en el sistema judicial. Estos comportamientos consiguen arraigarse en el sistema a través de la creación de estrechos vínculos que les permiten llevar a cabo sus fines delictivos, por lo que se convierten en una de las amenazas más serias para la independencia del sistema 
de justicia. El hecho de que los problemas generados por el crimen organizado transnacional trasciendan las fronteras físicas tradicionales establecidas por los estados hace necesaria la implementación de una acción coordinada a nivel internacional con el fin de combatir eficazmente esta lacra.

Tras el análisis de la numerosa documentación referenciada, se ha podido constatar empíricamente como el binomio entre agentes que operan desde el sector privado y políticos y funcionarios de la administración de justicia, se convierte en una condición "sine qua non" para que el crimen organizado transnacional pueda lograr sus objetivos. Es más, sin la connivencia de estos agentes las redes criminales nunca podrían llegar a alcanzar el grado de criminalidad que conlleva en muchas ocasiones la transnacionalidad.

Con el fin de hacer frente a los riesgos y amenazas que supone la delincuencia organizada para el Poder Judicial, es necesario aplicar un enfoque holístico que permita mantener una coordinación entre los diferentes actores y áreas de trabajo con el fin de obtener unos resultados globales que tengan una repercusión transversal en los sistemas públicos estatales. Además, es importante tener en cuenta que las iniciativas desarrolladas para hacer frente a la corrupción judicial solo serán eficaces si tienen en cuenta las circunstancias sociales, culturales, económicas, políticas o jurídicas concretas de cada entorno en las que se implementen.

Algunas de las posibles soluciones planteadas por los miembros del estamento judicial consistirían, entre otras, en crear jueces especializados en organizaciones criminales, hacer revisiones periódicas de los funcionarios, aumentar las rotaciones de sus cargos $u$ otorgar un plus salarial a los Magistrados y Magistradas que desarrollan sus funciones en zonas de riesgo. Por su parte, la Corte Plena del Poder Judicial de Costa Rica va un paso más allá al proponer, no solamente extremar los nombramientos de los funcionarios judiciales, sino además llevar a cabo una "revisión constante y periódica de vida y costumbres de las personas que laboran para el Poder Judicial" (Corte Plena, 2014, p.227-230)

Por su parte, el Informe del Relator sobre la independencia de magistrados y abogados, en su informe ante la Asamblea General del año 2017, adelantó algunas de las claves que habría que tener en cuenta a la hora de encarar la relación entre los delitos transnacionales y la corrupción judicial. En concreto, el documento destaca aspectos fundamentales como la necesidad de fortalecer el estado democrático y velar por el funcionamiento óptimo del sistema de administración de justicia para combatir la penetración del crimen organizado. Además, la promoción de la cooperación internacional como elemento esencial para hacer frente al problema, la dificultad de encontrar un punto de equilibrio entre la reforma del sistema judicial y su independencia o la importancia de la educación a la hora de sensibilizar a la opinión pública son algunos de los elementos que plantea (A/72/140, 2017, p. 23-24)

En este contexto, es importante destacar que el Poder Judicial debería tener márgenes de coordinación. La Declaración de Lima de la VIII Cumbre de las Américas reafirma la importancia de mantener y proteger la independencia judicial pero no establece medidas concretas para apoyar la función judicial, particularmente en el caso de crímenes transnacionales. Si el caso de corrupción de Odebrecht que afecta a varios países Latinoamericanos puede dejar alguna lección, esta es la de asegurar mecanismos de transparencia y acceso a la información, así como el aumento de mecanismos de cooperación internacional. Eduardo Salcedo-Albarán y Luis J. Garay-Salamanca por su 
parte han identificado como las estrategias para combatir las redes criminales "se concentran principalmente en perseguir a los capos de turno, mientras se omiten las estructuras económicas y políticas que sustentan dichas redes" (2016, p.XXX)

Finalmente, en aras de garantizar los resultados necesarios para una solución a largo plazo debemos tomar en consideración algunas circunstancias particulares. Primeramente, hay que tener en cuenta el papel primordial que el estado debe desempeñar para asegurar la consecución de los objetivos previstos mediante la asunción de una serie de deberes y obligaciones hacia el sistema judicial en general y las personas que lo integran en particular.

Para este propósito, se deben fortalecer los mecanismos de transparencia y acceso a la información pública, particularmente en lo que se refiere al nombramiento de juezas y jueces, así como los procesos de gestión judicial y asignación de casos.

Además, la función del estado no puede limitarse exclusivamente a garantizar la seguridad y los recursos a los jueces y abogados, sino que debe ir más allá al permitir una legislación adecuada, asegurar el apoyo político y promover las capacidades individuales. Tanto el Estado como las organizaciones que aglutinan al personal judicial deben ser conscientes de los desafíos que surgen al fortalecer las capacidades individuales de los miembros del sistema judicial. En este ámbito, elementos como la cooperación internacional, la educación, la formación permanente o la independencia e imparcialidad del estamento jurídico son algunos extremos a tomar en consideración.

Tal y como asevera Carlos Scartascini, resulta imprescindible que la comunidad internacional contribuya a fortalecer los diferentes sistemas judiciales, protegiéndolos de la manipulación a que son sometidos en ocasiones por parte del poder ejecutivo de turno (2015, p.Blog IADB) Para lograrlo, no solo hay que aplicar conocimientos y reformas en aras de incrementar su eficacia y transparencia, sino que hay lograr que los ciudadanos recuperen su confianza en aquellas instituciones que están destinadas a salvaguardar y garantizar sus derechos y libertades fundamentales.

\section{Bibliografía}

Alt, James E., Lassen, David D. (2008). Political and judicial checks on corruption: evidence from American state governments, Economics and Politics, Vol. 20, 33-61, Blackwell Publishing Ltd.

Argandoña, A. (2006). La Convención de las Naciones Unidas contra la Corrupción y su impacto sobre las empresas internacionales, Documento de Investigación $\mathrm{n}$ ㅇ 656, Navarra, Universidad de Navarra.

Carranza (2007), La convención de las Naciones Unidas contra la corrupción y la devolución de los activos a los países de origen, Costa Rica, Escuela Libre de Derecho, Colegio de Abogados.

Bellido Aspas, M., (2006). La fundamentación Fáctica y Jurídica de las Resoluciones Judiciales, en Derecho Procesal Penal, República Dominicana, Escuela Nacional de la Judicatura, 533-591.

Briscoe I., Perdomo, C., Uribe Burcher C., (2015). Redes llícitas y Política en América Latina, Estocolmo, IDEA International. 
La integridad e independencia del Poder Judicial como garantía frente a la amenaza (...) (91-110)

Buscaglia, E., Van Dijk, J. (2003). Controlling organized crime and corruption in the public sector, Forum on Crime and Society, vol. 3, Nos. 1 and 2.

Carbonell, M., (2014). Corrupción Judicial e impunidad: el caso Mexicano, México, Biblioteca Jurídica Virtual del Instituto de Investigaciones Jurídicas de la UNA.

Corporación Latinobarómetro, (2015). La Confianza en América Latina 1995-2015. Santiago de Chile, Latinobarómetro: Opinión Pública Latinoamericana.

Corporación Latinobarómetro, (2017). Informe Anual 2017, Santiago de Chile, Latinobarómetro: Opinión Pública Latinoamericana.

Egenhoff, T., Stein, E. (2011). Seguridad y Crimen Organizado Transnacional. Una propuesta de acción para Centroamérica, 2 Documento político, Guatemala, Red Centroamericana de Centros de Pensamiento e Incidencia/Fundación Konrad Adenauer.

Esteve Moltó, J. E., (2016). Les droits des victimes de disparition forcée devant la cour européenne des droits de l'homme : la nécessité de la fertilisation croisée avec le système interamericain, Annuaire Français de Droit International, LXI , París, CNRS Éditions.

Flores Pérez, C. A. (2007). Crimen Organizado: Conceptos, prácticas e implicaciones, Managua, Boletín Informativo del Instituto de Estudios Estratégicos y Políticas Públicas, Abril-Junio 2007.

Franco Chuaire, M., Scartascini, C., (2014). La política de las políticas públicas: Reexaminando la calidad de las políticas públicas y las capacidades del Estado en América Latina y el Caribe. IDB Documento de Política.

FRIDE, (2010). Democracy Monitoring Report Albania, Madrid, Fundación para las Relaciones Internacionales y el Diálogo Exterior.

Morten Koch, A. (2018). Why Corruption Matters in Human Rights, Journal of Human Rights Practice, Oxford University Press, 1-12.

Nye, J.S. (1967). Corruption and Political Development: A Cost-Benefit Analysis, en A.J. HEIDENHEIMER, et al., Political Corruption, New Brunswick, NJ, Transaction Books, 963-983.

Resa Nestares, C. (2005). Crimen organizado transnacional: definición, causas y consecuencias, Madrid, Universidad Autónoma de Madrid.

Salcedo-Albarán E., Garay-Salamanca L.J. (2016), Macro-criminalidad: Complejidad y Resiliencia de las Redes Criminales, Bloomington, IUniverse.

Scartascini C., (2015). Crimen y castigo: la independencia judicial en América Latina, Banco Interamericano de Desarrollo, blogs IADB, Washington. Disponible en https://blogs.iadb.org/Ideasquecuentan/2015/02/17/crimen-y-castigo-laindependencia-judicial-en-america-latina/

Sullivan, J. P (2016), "Prólogo Saliendo de las sombras; el poder de las redes" en Macrocriminalidad: Complejidad y Resiliencia de las Redes Criminales, Bloomington, IUniverse. 
Van Dijk, J., Spapens, T. (2014) Transnational Organized Crime Networks, en Handbook of Transnational Crime and Justice, Chapter 11, Los Ángeles, SAGE Publications, Inc.

\section{Organismos Internacionales}

Acta de Corte Plena. Sesión de Corte Plena. № 41-14. (2014). Informe de la Comisión para investigar la penetración del crimen organizado y del narcotráfico en el Poder Judicial, Costa Rica.

Asamblea Parlamentaria del Consejo de Europa, AS/Jur (2014) 19, (2014), Comité de Asuntos Jurídicos y Derechos Humanos, documento informativo preparado por la European Human Rights Association.

Banco Mundial (2011), “Crimen y Violencia en Centroamérica. Un Desafío para el DesarroIlo", Departamentos de Desarrollo Sostenible y Reducción de la Pobreza y Gestión Económica Región de América Latina y el Caribe.

Comisión Interamericana de Derechos Humanos (2011). OEA/Ser.L/V/II, Doc. 66, Segundo informe sobre la situación de las defensoras y los defensores de derechos humanos en las Américas.

Comisión Interamericana de Derechos Humanos (2013), OEA/Ser.L/V/II., Doc. 44, Garantías para la independencia de las y los operadores de justicia. Hacia el fortalecimiento del acceso a la justicia y el estado de derecho en las Américas.

Comisión Interamericana de Derechos Humanos (2018), Resolución 1/18: “Corrupción y Derechos Humanos".

Consejo de Europa, Comité de Ministros. Recomendación Rec (2000) 19 del Comité de Ministros a los Estados miembros sobre el papel del Ministerio Público en el sistema de justicia penal.

Organización de los Estados Americanos (OEA) (1996), Convención Interamericana contra la Corrupción, 29 de marzo de 1996.

Summit Implementation Review Group (2017), GRIC/CA-VIII/doc.2/17, "Democratic governance against corruption", Concept Paper, VIII Summit of the Americas.

\section{Documentos de Naciones Unidas}

Naciones Unidas, Asamblea General "Convención de las Naciones Unidas contra la delincuencia organizada transnacional“" A/RES/55/25 (8 de enero de 2001).

Naciones Unidas, Asamblea General “Declaración del Milenio", A/RES/55/2 (13 de septiembre de 2000).

Naciones Unidas, Asamblea General "Convención de las Naciones Unidas contra la Corrupción", A/RES/58/4 (31 de octubre de 2003).

Naciones Unidas, Asamblea General "Documento Final de la Cumbre Mundial 2005", A/RES/60/1 (25 de octubre de 2005).

Naciones Unidas, Asamblea General "Informe de la Relatora Especial sobre la independencia de los magistrados y abogados", Gabriela Knaul, A/65/274 (10 de agosto de 2010). 
Naciones Unidas, Asamblea General "Informe de la Relatora Especial sobre la independencia de los magistrados y abogados”, Gabriela Knaul, A/67/305 (13 de agosto de 2012).

Naciones Unidas, Asamblea General "Transformar nuestro mundo: la Agenda 2030 para el Desarrollo Sostenible“, A/70/L.1 (18 de septiembre de 2015).

Naciones Unidas, Asamblea General “Informe final del Comité Asesor del Consejo de Derechos Humanos sobre las consecuencias negativas de la corrupción en el disfrute de los derechos humanos", A/HRC/28/73 (5 de enero de 2015).

Naciones Unidas, Asamblea General "Informe de la Relatora Especial del Consejo de Derechos Humanos sobre la trata de personas, especialmente mujeres y niños", María Grazia Giammarinaro, A/71/303 (5 de agosto de 2016).

Naciones Unidas, Asamblea General "Informe provisional del Relator Especial sobre la tortura y otros tratos o penas crueles, inhumanos o degradantes", Juan E. Méndez, A/71/298 (5 de agosto de 2016).

Naciones Unidas, Asamblea General "Informe del Relator Especial sobre la independencia de los magistrados y abogados", Diego García-Sayán, A/72/140 (25 de julio de 2017).

Naciones Unidas, Conferencia de las Partes en la Convención de las Naciones Unidas contra la Delincuencia Organizada Transnacional, Asistencia técnica prestada para ayudar a los Estados a aplicar la Convención de las Naciones Unidas contra la Delincuencia Organizada Transnacional y sus Protocolos, CTOC/COP/2016/10 (20 de julio de 2016).

Naciones Unidas, Conferencia de las Partes en la Convención de las Naciones Unidas contra la Delincuencia Organizada Transnacional "Informe de la Conferencia de las Partes en la en la Convención de las Naciones Unidas contra la Delincuencia Organizada Transnacional", CTOC/COP/2016/15 (17 al 21 de octubre de 2016).

Naciones Unidas, Consejo de Derechos Humanos "Informe resumido acerca de la mesa redonda sobre las consecuencias negativas de la corrupción en el disfrute de los derechos humanos", A/HRC/23/26 (18 de abril de 2013).

Naciones Unidas, Consejo Económico y Social, "Informe del Relator Especial sobre la independencia de los magistrados y abogados", Sr. Leandro Despouy, E/CN.4/2004/60 (31 de diciembre de 2003).

Naciones Unidas, Secretaría, Boletín del Secretario General, Organización de la Oficina de las Naciones Unidas contra la Droga y el Delito, ST/SGB/2004/6 (15 de marzo de 200).

Naciones Unidas, Oficina de Naciones Unidas contra la Droga y el Delito (1999), “Global Programme against Corruption: an outline for action", Oficina de Naciones Unidas contra la Droga y el Delito.

Naciones Unidas, Oficina de Naciones Unidas contra la Droga y el Delito, Forum on Crime and Society, vol. 3, Nos. 1 and 2, Nueva York, 2003. 
Naciones Unidas, Oficina de Naciones Unidas contra la Droga y el Delito, Anti-Corruption Toolkit, 2004.

Naciones Unidas, Oficina de Naciones Unidas contra la Droga y el Delito, "Integrity in the Criminal Justice System", 2018, Disponible en https://www.unodc.org/unodc/en/corruption/criminal-justice-system.html

Naciones Unidas, Oficina de Naciones Unidas contra la Droga y el Delito, "UNODC's Action against Corruption and Economic Crime", 2018. Disponible en http://www.unodc.org/unodc/en/corruption/default.html

Naciones Unidas, Oficina de Naciones Unidas contra la Droga y el Delito, “Crimen Organizado Transnacional", 2018, Disponible en https://www.unodc.org/ropan/es/organized-crime.html

Naciones Unidas, Oficina de Naciones Unidas contra la Droga y el Delito, "Integrity in the Criminal Justice System", 2018. Disponible en https://www.unodc.org/unodc/en/corruption/criminal-justice-system.html 